\title{
Functional Systems and Brain Functional Units Beyond Luria, With Luria: Anatomical Aspects
}

\author{
Jordi Peña-Casanova \\ Hospital del Mar Medical Research Institute, \\ Autonomous University of Barcelona, \\ Spain, Catalonia, Barcelona \\ Jorge Sigg-Alonso \\ University of Mondragón, \\ Mexico, Mexico City
}

\section{Функциональные системы и функциональные блоки мозга после Лурия, с Лурия: анатомические аспекты}

\author{
Жорди Пенья-Казанова \\ Больница дель Мар, Медицинский научно-исследовательский институт, \\ Автономный университет Барселоны, \\ Испания, Каталония, Барселона \\ Хорхе Сигг-Алонсо \\ Мондрагонский университет, \\ Мексика, Мехико
}

Corresponding author.E-mail:jpcasanova51@gmail.com

This paper describes the anatomical aspects of a functional brain model that develops A. R. Luria's ideas. Five functional brain units are described on the basis of ontogenetic, anatomical, histological, functional, and clinical studies: preferential or primordial (unit I), limbic (unit II), cortical (unit III), basal ganglia (unit IV), and cerebellar (unit V). This review allows two large integrated and interrelated functional complexes to be distinguished: a primordial-limbic complex (units I and II) and a supralimbic one (units, III, IV and V). There is consensus that there exists a clear interplay among the cortex, the basal ganglia, and the cerebellum. Three main simplified parallel cortico-basal ganglia systems have been recognized: limbic, associative, and sensorimotor. Certain structures (e. g. neuromodulatory systems, hypothalamus, and paralimbic cortex) form functional links among units. Future studies are required to develop and improve the proposed model. 
Keywords: systems biology; complex systems; cerebral cortex; thalamus; cerebellum; basal ganglia; learning systems.

В данной статье развиваются идеи А. Р. Лурия, касающиеся анатомических аспектов функциональной модели мозга. На основании онтогенетических, анатомических, гистологических, функциональных и клинических исследований описаны пять функциональных блоков мозга: преимущественные или первичные (блок I), лимбические (блок II), корковые (блок III), базальные ганглии (блок IV) и мозжечок (блок V). Этот обзор позволяет выделить два крупных интегрированных и взаимосвязанных функциональных комплекса: примордиально-лимбический комплекс (блоки I, II) и супралимбический комплекс (блоки III, IV, V). Существует консенсус, который представляет собой четкое взаимодействие между корой головного мозга, базальными ганглиями и мозжечком. Различают три основные упрощенные параллельные системы кортико-базальных ганглиев: лимбическую, ассоциативную и сенсомоторную. Некоторые структуры (например, нейромодулирующие системы, гипоталамус и паралимбическая кора) образуют функциональные связи между блоками. Для разработки и улучшения предлагаемой модели необходимы дальнейшие исследования.

Ключевые слова: системная биология; сложные системы; кора головного мозга; таламус; мозжечок; базальный ганглий; системы обучения.

\section{Introduction}

As proposed by A. R. Luria, mental functions, as complex structures, are organized in systems of concertedly working zones, each of which performs its role and may be located in completely different, and often far distant, areas of the brain (Luria, 1973a). Luria also recognized the existence of grounds for distinguishing three main functional units of the brain whose participation is necessary for any type of mental activity (Luria, 1973a). These units were described as: (I) unit for regulating tone and waking and mental states (brain stem, diencephalon, and mesial regions of the cortex); (II) unit for obtaining, processing and storing information coming from the outside world (lateral postcentral regions of the neocortex on the convex surface of the hemispheres); and (III) a unit for programming, regulating and verifying mental activity (precentral anterior regions of the hemispheres) (Luria, 1973b).

In a recent paper (Peña-Casanova, 2018), Luria's model of three functional units of the brain was reviewed. In this process an ad hoc search of published medical literature on the subject was carried out. A total number of 15 guidelines was defined in order to develop a new model. The proposed model was characterized by the following elements: Luriass unit I was maintained, but expanded with new components; a limbic unit was differentiated; Luria's units II and III were unified in a single unit; and two new units were added: striatal (basal ganglia) systems (unit IV) and cerebellar ones (unit V). 
It includes elements that are missing from Luria's model and avoids the corticocentric approach characteristic of classical neuropsychology. It was concluded that the new approach would allow a better analysis of the effects of brain pathology on cognition, neuropsychiatry, and behavior. Within the proposed framework, the concept of complex functional system was maintained and expanded.

\section{Objectives}

This paper intends to go several steps further in the development of a five-block brain functional model. Specifically, it will deal with anatomical aspects not previously discussed. We will try to develop the idea that anatomical structures do not allow the clear establishment of separate functional systems. In that regard, functional units are abstractions within the global and integrated function of the brain (Luria, 1973a). It will also be shown that brain organization presents inter-related functional systems, with structures that act as functional hubs. Finally, this paper will try to generate an anatomical working sketch for future developments of the model.

\section{Methods}

A specific PubMed search (from January 2018 to December 2019) was performed in the following fields: cortex, telencephalon, hippocampus, amygdala, thalamus, basal ganglia, cerebellum, connectome, and learning.

\section{Development}

The first two sections of this review will be devoted to the ontogenetic and phylogenetic basis of the brain systems and the theory of functional systems, respectively. Two more sections will be concerned with the proposed functional units. In these sections the main anatomical structures that compose each unit will be commented on (Tables 1 to 5).

\section{Ontogenesis, Phylogenesis, and the Functional Organization of the Brain}

On the fifth day of gestation, the rostral extremity of the neural tube resembles a median holosphere with two primordia or anlagen [from the German word] distributed symmetrically - right and left sides. These primordia represent the subcortical structures of the brain, and the cerebellar hemispheres will be one of the results of their development (Yakovlev, 1948; Lecours \& Simard, 1998). In this part of the brain, the right and the left parts grow equally, with no laterality effect on the body.

Brain development shows, in the five vesicle phase (5 weeks of gestation), three main divisions: (1) rombencephalon (myelencephalon [medulla oblongata], and metence- 
phalon [pons, and cerebellum]); (2) mesencephalon (midbrain); and (3) prosencephalon. The prosencephalon (forebrain) is further divided into (4) the diencephalon (hypothalamus, thalamus and epithalamus), and (5) the telencephalon (cerebral hemispheres: cortex, subcortical white matter, basal ganglia and basal forebrain nuclei) (Yakovlev, 1948; Lautin, 2002; Blumenfeld, 2010). From embryogenesis studies, P. I. Yakovlev (1948) proposed a tripartite neuroanatomic and behavioral architecture of the cortex (pallium): entopallium, mesopallium, and ectopallium, arranged in concentric rings. The entopallium is intimately bound to the rostral end of the brainstem, the hypothalamus. Each of these pallial layers constitutes a different telencephalic division, respectively: (1) telencephalon impar, (2) telencephalon semipar, and (3) telencephalon totopar. The boundary between telencephalon semipar and totopar is gradual (see Lautin (2002) for comparative and historical details). Yakovlev related each of the three brains to a different type of motility:

- The telencephalon impar (median zone, rhinic) includes the septum, the para-olfactory areas (subcallosal areas of Broca), the olfactory bulbs (paleocortex), and the hippocampi (archicortex). The rhinic brain is devoted to the endokinesis or the cell-bound movement, related to visceral motility (e.g. peristalsis).

- The telencephalon semipar (limbic zone, paramedian), includes the cingular gyrus, the isthmus of the cingulate, the parahippocampal gyrus, the limen isulae, and the insula. The semipar brain, according to Lautin (2002), is considered isomorphic with Brocas's lobe (gyrus fornicatus, olfactory lobe). The mode of projection of telencephalon semipar is ambilateral, and is related to ereismokinesis or body-bound movement, dedicated to the expression of emotions (e. g. pain, mimicry, swearing).

- The telencephalon totopar (supralimbic zone). The ontogenetic evaginations of this telencephalon are the primordia (anlagen) of the frontal, parietal, temporal, and occipital lobes (Yakovlev, 1948). The telencephalon totopar has a contralateral mode of projection and it is related to telokinesis or object bound voluntary motility (e.g. tool use).

Yakovlev's theory is clearly vertical (parallel rings) and based on cyto- and myeloarchitectonics in relation to assumed functions. Yakovlev's distinctions allows the recognition of three major brain zones: median, limbic, and supralimbic (neocortical). In fact, Luria distinguished a first functional brain unit (I) in which Yakovlev's median and limbic zones were considered as a whole. This whole has a clear physiological sense, especially in the field of emotions, and in cortical activation and modulation.

In fact, Luria (1973a) divided Yakovlev's supralimbic structures anatomically and functionally into two units: posterior (II), and anterior (III), a differentiation based on anatomy (Rolando's fissure as reference). Although it is undoubedly of clinical interest, it has currently no consistent physiological basis. The division of the cerebral cortex into cytoarchitectonic global zones (Mesulam, 2000), and its subcortical connections, makes much more sense. In addition, functional studies show a clear differentiation of a series of global networks beyond the anterior-posterior dichotomy (Yeo et al., 2011) [see below]. On the other hand, due to the prevailing ideas during the last century (Parvizi, 2009), the specific role of the basal ganglia and the cerebellum was not considered in Luria's model. 
Exaptation. Phylogenesis provides a very interesting background in order to understand brain function. Recent studies have demonstrated that basal ganglia circuitry is present in the phylogenetically oldest vertebrates. This kind of circuitry has been conserved, most likely as a mechanism for action selection used by all vertebrates (Stephenson-Jones, Samuelsson, Ericsson, Robertson, \& Grillner, 2011; Grillner \& Robertson, 2016). Exaptation represents a process by which an ancestral core unit has been co-opted for multiple functions (Gould \& Vrba, 1982). In this regard, emotional/affective and cognitive regulations are considered as extensions of the motor control system. Consequently, for the basal ganglia, motor functioning, emotion, and cognition constitute similar and parallel processes (Koziol \& Budding, 2009). The evolution of the brain also shows a parallel growth of the cortex (mainly frontal and inferior parietal lobes), the caudate nucleus, and the lateral hemispheres and dentate nucleus of the cerebellum (Parvizi, 2009). This development (by exaptation) generates two parallel vertically organized cortical-subcortical-cortical series of loops: the basal ganglia system (cortex, basal ganglia, thalamus, and back to the cortex), and the cerebellar system (cortex-pons, cerebellum, thalamus, and back to cortex). This fact explains the functional continuity between the limbic (ventral striatum) and supralimbic (dorsal striatum) systems (Doya, 2000a; Koziol \& Budding, 2009; Blumenfeld, 2010).

\section{Functional Systems}

The theory of functional systems (Anokhin, 1935) represents a view opposed to reflexes. Reflexes are based on a linear processing of information (stimulus-response), from receptors to effectors. Unlike reflexes, the basic principle of functional systems is the physiological self-organizing non-linear relationship between distributed local systems to establish a holistic system or "integrated unit" (Luria, 1973a). In contrast to reflexes, the goals of functional systems are not specific actions by themselves but the adaptive results of these actions: "The presence of a constant (invariant) task, performed by variable (variant) mechanisms, bringing the process to a constant (invariant) result" was considered one of the basic features distinguishing functional systems (Luria, 1973b, p. 28).

In this field, it is crucial to recognize two types of functional systems, and their differentiated contribution to the homeostasis of the individual (Luria, 1973a):

- Functional systems type I (Elementary). These kinds of functional systems provide homeostasis thanks to internal resources of the body, inside its boundaries. Homeostasis is a state of internal physical and chemical equilibrium that maintains life (Bernard, 1866; Cannon, 1932). Such an equilibrium includes a series of variables, including body temperature, heart rate, ion concentration, fluid balance, extracellular fluid $\mathrm{pH}$, and blood glucose level. Each of these variables is regulated by one or more homeostatic mechanisms. All these functions depend on primitive evolutionary systems located primarily in the brainstem and in Yakovlev's telencephalic medial, or rhinic zone, intimately bound to the hypothalamus. Even in a situation of sleep, biologically interoceptive relevant information (cold, bladder distention) can promote awakening (Seeley \& Strum, 2007). Representations of the internal state allow critical signals to be activated and motivated in order to solve basic ho- 
meostatic needs. The cries of the newborn represent homeostatic needs, and also integrated limbic unpleasantness. Crying (alarm) involves the activation of the maternal environment (mother) to meet the homeostatic needs of the newborn.

- Functional systems type II (Complex). These second kind of functional systems support homeostasis thanks to the execution of different types of behavior interacting with the outside world (Anokhin, 1935; Luria, 1973a). The second type "are organized into complex behavioral systems, as a result of whose action the appropriate needs are satisfied and the necessary balance of the internal economy of the organism' is restored" (Luria, 1973b, p. 53). In humans, homeostatic interoceptive afferent information reaches the dorsal posterior insula, via the posterior ventromedial thalamus. This information is forwarded to the anterior insula, of the nondominant hemisphere, providing the biological substrate for conscious, evaluative interoception. Thanks to insular connections to the amygdala, the anterior cingulate cortex and frontal cortex, interoceptive signals may generate contextually optimized behaviors (see Seeley and Sturm, 2007). Beyond biological needs, complex functional systems type II, are the foundation of complex forms of socio-cultural behavior (Vygotsky, 1960, 1965 [on extra-cortical organization]; Luria, 1974). At this point the importance of the socio-historical approach appears (Leontiev, 1959 [on "new functional organs"]; Luria, 1974; Ardila, 2018). Luria also recognized that the localization of higher mental processes in the human cortex is never static or constant. He stated that localization "moves about essentially during development of the child and at subsequent stages of training" (Luria, 1973b, p. 31). The important contribution of both Luria and Vygotsky to developmental neuropsychology has been recognized (Akhutina \& Pylaeva, 2011).

\section{Unit 1: Preferential or Primordial Systems}

Major neural structures that compose unit I. This unit is composed of the medial and most primitive structures of the brain: the brainstem (medulla, pons, and mesencephalon) and diencephalon (see Table 1). Certain components of this unit (e.g. reticular and neuromodulatory systems) expand into the entire brain (Blumenfeld, 2010).

\section{Table 1}

Unit I (preferential or primordial systems): Main structures

\section{A. Brainstem (medulla, pons, and mesencephalon [midbrain])}

1. Cranial nerve nuclei and additional related structures (nuclei and pathways)

- Associated with eye movements: pretectal area; superior colliculus, MLF (and its rostral interstitial nucleus); convergence center; paramedian pontine RF; accessory hypoglossal nucleus

- Associated with hearing: superior olivary nuclear complex; trapezoid body; lateral lemniscus; inferior colliculus

- Associated with cranial nerve functions: RF, central tegmental tract 


\section{Long tracts}

- Motor pathways: corticospinal, rubrospinal, vestibulospinal, reticulospinal, tectospinal

- Somatosensory pathways: medial lemniscal pathway (fine touch, vibration, joint position); anterolateral pathways (pain, temperature, crude touch)

\section{Cerebellar circuitry}

- Cerebellar peduncles

- Pontine nuclei, red nucleus (parvocellular), central tegmental tract, inferior olivary nucleus

\section{Reticular formation and related structures}

- Systems with diffuse (widespread) projections

- Reticular formation (locations and targets [T])

- Rostral. Midbrain and upper pons (pontomesencephalic). T: thalamic intralaminar nuclei, hypothalamus, basal forebrain (alertness, conscious state)

- Thalamic intralaminar nuclei. T: cortex, striatum (alertness, conscious state)

- Midline thalamic nuclei. T: cortex (alertness, conscious state)

- Caudal. Pons and medulla. T: Cranial nerve nuclei and spinal cord links (motor, reflex and autonomic functions)

- Specific neuromodulatory systems (locations and targets [T])

- Norepinephrine. Pons: nucleus ceruleus and lateral tegmental area. T: global CNS (alertness, mood elevation)

- Dopamine. (1) SNc. T: (mesostriatal pathway): neostriatum (motor function): (2) VTA. T: (mesolimbic pathway): limbic cortex, nucleus accumbens, amygdala, cingulate gyrus; (3) VTA and scattered cells near the SN. T: (nesocortical pathway): prefrontal cortex (frontal function, working memory, attention)

- Serotonin. Midbrain and pons: raphe nuclei. T: global CNS (mood elevation)

- Acetylcholine

- Basal forebrain: NBM, Medial septal nucleus, BNDB. T: cortex (alertness, memory)

- Pontomesencephalic zone: pedunculopontine nucleus and laterodorsal tegmental nucleus. T: thalamus, cerebellum, pons, medulla (alertness, memory)

- Histamine. Midbrain: reticular formation; hypothalamus: tuberomammillary nucleus. T: global brain (alertness)

- Nuclei involved in sleep regulation

- Pain modulatory systems (periaqueductal gray; rostral ventral medulla)

- Brainstem motor control systems

- Posture and locomotion (reticular formation; vestibular nuclei; superior colliculi; red nucleus [magnocellular]; SN; pedunculopontine tegmental nucleus

- Respiration, cough, hiccup, sneeze, shiver, swallow, nausea, and vomiting (chemotactic activation zone)

- Autonomic control (including blood pressure and heart rate; sphincter control, including pontine micturition center) 


\section{B. Diencephalon}

- Thalamus; epithalamus (habenula and pineal body); hypothalamus

C. Autonomic systems (central)

- Sympathetic division; parasympathetic division; enteric division

Note. $\mathrm{MLF}=$ medial longitudinal fasciculus; $\mathrm{RF}=$ reticular formation; $\mathrm{SNc}=$ substantia nigra pars compacta; $\mathrm{VTA}=$ ventral tegmental area; $\mathrm{SN}=$ substantia nigra; $\mathrm{NBM}=$ nucleus basalis of Meynert; $\mathrm{BNDB}=$ bed nucleus of the stria terminalis.

The brainstem is, evolutionarily-speaking, the oldest part of the human brain. It is the part of the brain that most closely resembles those of fish and reptiles (Blumenfeld, 2010). Several structures of the brainstem are significantly involved in basic bodily functions necessary for biological survival, and in behavior. The diencephalon, located between the midbrain and the telencephalon, also plays a crucial role in autonomic processing. As previously commented, the telencephalon impar (median zone, rhinic) includes the septum, the para-olfactory areas (subcallosal areas of Broca), the olfactory bulbs (paleocortex), and the hippocampi (archicortex). These structures will be studied within the context of unit II. For an anatomical and clinical approach see Blumenfeld (2010) and Clark, Boutros, and Mendez (2018).

Unit I systems are termed preferential (or primordial) because they have a functional priority due to their participation in life-supporting processes (Peña-Casanova, 2018). As discussed in later sections, certain structures (e.g. hypothalamus) are shared with unit II.

Phylogenetically, the limbic system (unit II, see below) is highly interconnected with homeostatic regulation systems (Luria, 1973a; Mesulam, 2000). The hypothalamus (e.g. paraventricular nucleus [as overlapping structure]) plays a role of physiological interconnection with the amygdala, the hippocampus, and the autonomic systems (Hariri, 2015). This is why it is recognized, as previously stated, as an integrated primordial-limbic complex (units I and II of the proposed model), in concurrence with Luria (a single unit, I).

Traditionally, it is assumed that neuromodulators are involved in the control of general arousal. The specific function of primitive dopaminergic systems (mesostriatal [nigrostriatal], mesolimbic, and mesocortical) is crucial for motor, emotional, and cognitive functions (for a clinical view see Blumenfeld, 2010). Currently, it is possible to build a more specific and comprehensive view concerning the physiological functions of neuromodulators. In fact, a computational theory proposes that neuromodulators regulate distributed learning systems in the brain (Doya, 2000b, 2002).

\section{Unit II: Limbic System}

Major neural structures that compose unit II. This unit is composed of limbic areas, paralimbic cortex (mesocortex), and related structures (see Table 2). 
Table 2

Unit II (limbic system). Main structures and principal pathways

\section{Limbic components}

- Corticoid structures

- Septal region, diagonal band of Broca, substantia innominata (nucleus basalis of Meynert $[\mathrm{NBM}]$, and bed nucleus of the stria terminalis [BNST]), and amygdaloid complex (amygdala)

- Stria terminalis = amygdala-hypothalamus and septal nuclei connection

- Ventral amygdalofugal pathway = amygdala - hypothalamus, nucleus basalis, ventral striatum, and brainstem nuclei connections

- Medial forebrain bundle = Amygdala (and other forebrain structures and brainstem nuclei) reciprocal connections

- Allocortex

- Paleocortex: piriform cortex (primary olfactory cortex)

- Archicortex: Hippocampus. Hippocampal formation = dentate gyrus, hippocampus, subiculum, presubiculum, parasubiculum, entorhinal cortex

- Papez circuit = hippocampus - mammillary body (via the fornix) - anterior thalamic nuclei (via the mammillothalamic tract) - cingulate gyrus, presubiculum, entorhinal cortex, hippocampus (via the performant and the alvear pathways)

\section{Paralimbic zone (mesocortex)}

- Orbitofrontal cortex

- Insula

- Temporal pole

- Parahippocampal cortices

- Presubiculum, parasubiculum, entorhinal, prorhinal, and perirhinal (transentorhinal) area

- Cingulate complex

- Retrosplenial, ventral cingulate, and paraolfactory areas

\section{Limbic basal ganglia and other structures}

- Limbic basal ganglia

- Limbic striatum: nucleus accumbens septi (AcS), and olfactory tubercle (OT),

- Limbic pallidum: NBM, and BNST

- Ventral tegmental area (VTA) of Tsai (Midbrain)

- Mesolimbic pathway = VTA-limbic connection (mainly amygdala, cingulate gyrus, nucleus accumbens, temporal cortex)

- Habenula (Diencephalon. Epithalamic structure)

- Stria medullaris = septo-habenular connection

- Habenulointerpeduncular tract (f. retroreflexus) = interpeduncular nuclei (IP) (midbrain) connection (The IP projects to raphe nuclei and to dopaminergic nuclei) 
Table 2 (continued)

\section{Limbic and paralimbic thalamic nuclei}

- Anterior dorsal, anterior ventral, anterior medial, laterodorsal, mediodorsal, medial pulvinar, and other midline nuclei

\section{Hypothalamus}

Note. The NBN belongs to the limbic zone of the cortex and is also an extension of the reticular core of the BS. After Mesulam (2000).

Although Luria (1973a) discussed the functional role of the paleocortical and archicortical structures, and commented on the significance of Klüver and Bucy, and Bechterev-Korsakov, syndromes, he did not differentiate a limbic unit.

Beyond Yakovlev's telencephalic differentiations, the unit discussed here is based on current structural, physiological, and neurobehavioral data that characterize the limbic system. It is worth commenting that this unit has been previously proposed by other authors (e.g. Jubert, 1983; Téllez \& Sánchez, 2016).

As already mentioned, the hypothalamus constitutes a relevant structure in the integrated primordial-limbic functional complex. Similarly, the limbic striatum and the limbic pallidum are part of the striatal systems (unit IV) of the integrated supralimbic functional complex.

Limbic structures have three main functions: olfaction (piriform cortex), context / episodic memory (hippocampus), and emotions, feelings and drives (amygdala) (Mesulam, 2000; Blumenfeld, 2010; Clark et al., 2018). The role of the main limbic structures (corticoid and allocortex) will be briefly discussed in the following paragraphs. For more information see Clark et al. (2018).

Limbic areas (corticoid and allocortex). Corticoid areas (see above) show cytoarchitectonic features that have cortical and nuclear characteristics (Mesulam, 2000). They also present massive bilateral connections with the hypothalamus. The main characteristics of these structures are summarized below:

- Main basal forebrain related structures. Septal area, diagonal band of Broca, and substantia innominata (NBM and BNST) constitute part of the basal forebrain. These structures form a collection of cholinergic, GABAergic, and glutamatergic projection neurons and local GABAergic interneurons. They are made up of three main complexes. Two complexes projecting to the hippocampus, to the olfactory bulb and the piriform cortex, and one complex (NBM-substantia innominata) projecting uniformly to the neocortex.

- Amygdala and related structures. The amygdala receives information from the sensory cortices (high-resolution information), and from the thalamus (lowresolution information). The amygdala acts as an emotional hub and contributes to reward/motivation processing. It is considered as an evolved system for relevance detection (Sander, Grafman, \& Zalla, 2003). It sends inputs to the hypothalamus (hypothalamic-pituitary-adrenal axis activation), brainstem (sympathetic arousal), 
substantia innominata (alertness), insula (interoception, pain), hippocampal formation (contextual memory), and the prefrontal cortex (PFC) - attention, cognition (Whalen \& Phelps, 2009). The PFC regulates the function of the amygdala (inhibition) (Hariri, 2015). Physiologically, emotions cannot be separated from the autonomic systems.

- Olfactory (piriform) primary cortex and related structures. The piriform cortex receives information from the olfactory bulb, and is bilaterally connected with the hypothalamus. It is directly connected with practically all the mesocortical and limbic areas. The olfactory sense plays a key role in territorial, sexual, and feeding behaviors (Mesulam, 2000).

- Hippocampal formation. The hippocampal formation (HF) receives reciprocal information from sensory association areas, and from the dorsolateral PFC (for a comprehensive review see Andersen, Morris, Amaral, Bliss, and O'Keefe, 2007). The dorsolateral PFC is modulated by dopaminergic mesencephalic afferents. The HF is related to the information about the context (where? when? what? who?) of lived experiences. Thanks to its particular functional organization, the HF combines all contextual information. Context is defined as "the set of circumstances around an event" (Maren, Phan, \& Liberzon, 2013, p. 418). Contexts (spatial, temporal, interoceptive, cognitive, social, and cultural) are crucial for abstraction of situationally informed meanings of the world, and adaptation. The connections of the hippocampus with the ventral striatum (VS) contribute to the learning of the contexts in which a specific motivation is satisfied, through a specific behavior (Hariri, 2015). When the context reappears, the HF contributes to the opening of the ventral striatum. This gate will activate, on the one hand the dorsal striatum/pallidum (towards the thalamus and the motor cortex), and on the other hand, the ventral pallidum. In addition, the VS will activate the hypothalamic function (Hariri, 2015). Recent studies suggest that the hippocampus, beyond memory, contributes in the domains of decision-making, language, social cognition, and a variety of other capacities that are critical for flexible cognition (Hannula \& Duff, 2017).

Mesocortex (paralimbic cortex). This type of cortex is intercalated between the allocortex and isocortex (Yakovlev, 1948; Mesulam, 2000; Pandya, Seltzer, Petrides, \& Cipolloni, 2015). Phylogenetic research in mammals has demonstrated two waves of transition, or trends, from the allocortex to isocortex: the olfactocentric and hippocampocentric trends (Sanides, 1969; Mesulam, 2000). These two trends generate the paralimbic ring. The olfactocentric (piriform cortex, olfactory paleocortex) trend provides the orbitofrontal, insular, anterior parahippocampal, and temporopolar mesocortex. The olfactocentric trend is closely associated with the amygdala. The hippocampus and the induseum griseum (archicortex) constitute the primordia for the entorhinal cortex, the cingulate gyrus, and the posterior parahippocampal mesocortex (Pandya et al., 2015). For a comprehensive review on the cingulate neurobiology and disease see Vogt (2009). 


\section{Unit III: Cortical Systems}

Major neural structures that compose unit III. This unit includes all the cortices (limbic, paralimbic, and supralimbic) (see Table 3), related thalamic systems, and cortico-cortical pathways (intra- and interhemispheric association). In fact, unit III consists of the entire cortex and their cortico-cortical connectome (Catani \& Thiebaut de Schotten, 2012). The cortical unit, together with the basal ganglia and the cerebellar systems, constitute a large integrated limbic-supralimbic complex. Due to the exaptation of the primitive circuits of the basal ganglia, the ventral striatum performs a functional interplay with the dorsal striatum (Hariri, 2015; Yin H. H. \& Knowlton, 2006).

\section{Table 3}

Unit III (cortical systems): Main structures. Cortical types (supralimbic and paralimbic) and corresponding Brodmann areas (BA). After Mesulam (2000), and Blumenfeld (2010)

\section{Paralimbic mesocortex}

- Orbitofrontal cortex: [BA11-12 (posterior parts), BA13]

- Insula [BA14-16]

- Temporal pole [BA38]

- Parahippocampal cortices [BA27-28, 35]

- Cingulate complex [BA23-26, 29-33]

\section{Homotypical isocortex (classical secondary areas)}

- Modality specific (unimodal) association areas

- Motor: premotor cortex [anterolateral BA6]; FEF [BA8-6], SMA (medial face of the hemisphere) [Mainly BA6], supplementary eye fields [BA6], Posterior part of Broca's area [BA44]

- Visual: peristriate [BA18-19], parts of the fusiform, inferior temporal and middle temporal gyri [BA37, 20, 21]

- Auditory: mid- to anterior superior temporal gyrus [BA22]; middle temporal gyrus [BA21]

- Somatosensory: anterior rim of the superior parietal lobule [BA5]; rest of the superior parietal lobule [BA7]; parts of the posterior insula; anterior segment of the supramarginal gyrus [BA40]; S2 area in the parietal operculum (next to the dorsal insula)

- High-order (heteromodal) association areas (classical tertiary areas)

- Prefrontal association cortex [BA9, 10, 11, 12, 45, 46, 47]

- Parieto-temporal association cortex: posterior parietal [BA7]; supramarginalis [BA40]; angularis; BA 39]

\section{Idiotypic cortex (primary sensory-motor areas)}

- Primary motor (M1) [BA4]

- Primary somatosensory (S1) [BA3a, 3b, 1, 2]

- Primary visual (striate, calcarine, or V1) [BA17]

- Primary auditory koniocortex (A1) [BA41-42] 


\section{Addenda}

4. Claustrum (telencephalic pallial subcortical structure)

- Dorsal or insular

- Ventral

Note. $\mathrm{FEF}=$ frontal eye fields; SMA = supplementary motor area. Broca's region includes premotor cortex [BA44] (opercularis), and adjacent heteromodal cortex: triangularis [BA45], orbitalis [BA47], and frontal dorsolateral [BA46, 9]. Wernicke's region includes the following areas: posterior BA22, and parts of the adjacent heteromodal cortex [BA39-40], and possibly parts of the middle posterior gyrus.

A cytoarchitectonic study of the cerebral cortex shows that the cerebral hemispheres can be subdivided in numerous areas based on variations in neuronal architecture (cell types, number of layers, and canonical microcircuits). Five large functional cortical subtypes have been recognized: limbic, paralimbic, heteromodal association, unimodal association, and primary sensory-motor (Mesulam, 2000) (see Table 3). Such differentiation is crucial for the analysis of cerebral focal syndromes and their pathophysiology.

To be more exhaustive, a special subcortical structure has been included in this unit: the claustrum. The claustrum is a telencephalic, pallial structure that consists of the main divisions: dorsal or insular claustrum placed medial to the insular cortices, and the ventral claustrum placed medial to the piriform cortex (Druga, 2014). The claustrum integrates cortico-cortical links and has been recognized as a central node for consciousness (Yin B., Terhune, Symthies, \& Meck, 2016). For more information see Mathur (2014), Binks, Watson, and Puelles (2019), Torgerson and Van Horn (2014).

Unit III is related to semantic memory, episodic (contextual) memory, unsupervised learning (Doya, 2000a), and the associative global processing of circulating brain information. The cortex allows the establishment of flexible FS, and the final behavioral output (McFarland \& Sibly, 1975) according to cortical computations and extra-cortical inputs.

Unit III highlights local cortical processing in the global functional context of the brain. By highlighting this differentiated unit, it is possible to properly analyze cortical and cortico-subcortical focal syndromes (e.g. aphasia, apraxia, and agnosia). Restricted cortical lesions will give rise to symptoms depending on the type and modality of local processing (Luria, 1973a). It should also be noted that the analysis of cerebral local syndromes should be performed with a double (hodotopic) approach: topological (location) and hodological (affected connections). See Catani and Thiebaut de Schotten (2012).

The thalamus integrates multimodal information across diverse functional networks (Hwang, Bertolero, Liu, \& D’Esposito, 2017; Dehghani \& Wimmer, 2019), and acts as a gateway to mental representations [the "cognitive thalamus"] (Wolff \& Vann, 2019). Pulvino-cortical feedforward and feedback pathways participate in cognitive computations (Jaramillo, Mejias, \& Wang, 2019), and the nucleus reuniens sits at the nexus of a hippocampus and medial prefrontal cortex circuit enabling memory and behavior 
(Dolleman-van der Weel et al., 2019). As a paradigm of functional cortical interactions, the precuneus, the lateral temporal cortex, the medial PFC, and the posterior parietal cortices participate in multiple paralimbic networks that together comprise subsystems of the default mode network (Yeo et al., 2011).

The role of connection pathways (connectomics) is essential to understand cortical and brain function (Kennedy, Van Essen, \& Christen, 2016; Sporns, 2016). The adult human structural connectome shows a hierarchical complexity (Smith et al., 2019), with centralized and distributed cognitive task processing (Amico, Arenas, \& Goñi, 2019). Recent studies have reported a shared vulnerability for connectome alterations across psychiatric and neurological brain disorders (Lange et al., 2019; van den Heuvel \& Sporns, 2019; Baker et al., 2019).

Cortical learning: unsupervised learning. This type of learning implies a concise representation of sensory state, context, and action. In fact, it entails finding the appropriate modular architecture of a given task (Doya, 2000a). It is guided by the statistical properties of the input signal itself. This process may be regulated by ascending neuromodulatory inputs (Doya, 2000b).

\section{Unit IV: Basal Ganglia Systems}

Major neural structures that compose unit IV. This unit is composed of three main, highly simplified, parallel, cortico-basal ganglia systems: limbic, associative, and sensorimotor (Yin H.H. \& Knowlton, 2006), see Table 4, Figure 1. These main systems are further divided into a myriad of circuits. The basal ganglia comprise a group of subcortical structures distributed within the telencephalon, diencephalon, and mesencephalon. It also includes the pedunculopontine (pedunculotegmental) nucleus, a midbrain-pontine nucleus, and parts of the basal forebrain.

Cortico-striatal systems form an integrated cortical-subcortical system of motor and emotion control, behavioral selection (decision-making), reinforcement (reward) learning, language, praxis, gnosis, and procedural memory (Cox \& Witten, 2019; Simonyan, 2019). The canonical basal ganglia (BG) circuits (cortex — striatum — pallidum — thalamus - cortex) perform a process of selective disinhibition of the thalamus (Doya, 2002; Koziol \& Budding, 2009; Blumenfeld, 2010; Henke, 2010). Midbrain dopaminergic systems modulate basal ganglia circuits. Recent advances have shown a role of basal ganglia in psychiatric disorders (Macpherson \& Hikida, 2019).

Table 4

Unit IV (corticostriatal systems): Main structures

\section{Limbic network}

- Cortex: Prefrontal cortex (orbital and ventral)

- Basal ganglia

- Limbic striatum (nucleus accumbens septi [ACs], olfactory tubercle [OT])

- Ventral pallidum (nucleus basalis of Meynert [NBM], bed nucleus of the stria terminals [BNST]) 
- Thalamus: mediodorsal

\section{Associative (cognitive) network}

- Cortex: Prefrontal and parietal association cortices (fronto-parietal network)

- Basal ganglia

- Associative striatum (caudate / dorsomedial striatum)

- Associative pallidum

- Thalamus: mediodorsal / ventral

\section{Sensorimotor network}

- Cortex: Sensorimotor cortex

- Basal ganglia

- Sensorimotor striatum (putamen / dorsolateral striatum)

- Motor pallidum

- Thalamus: ventral

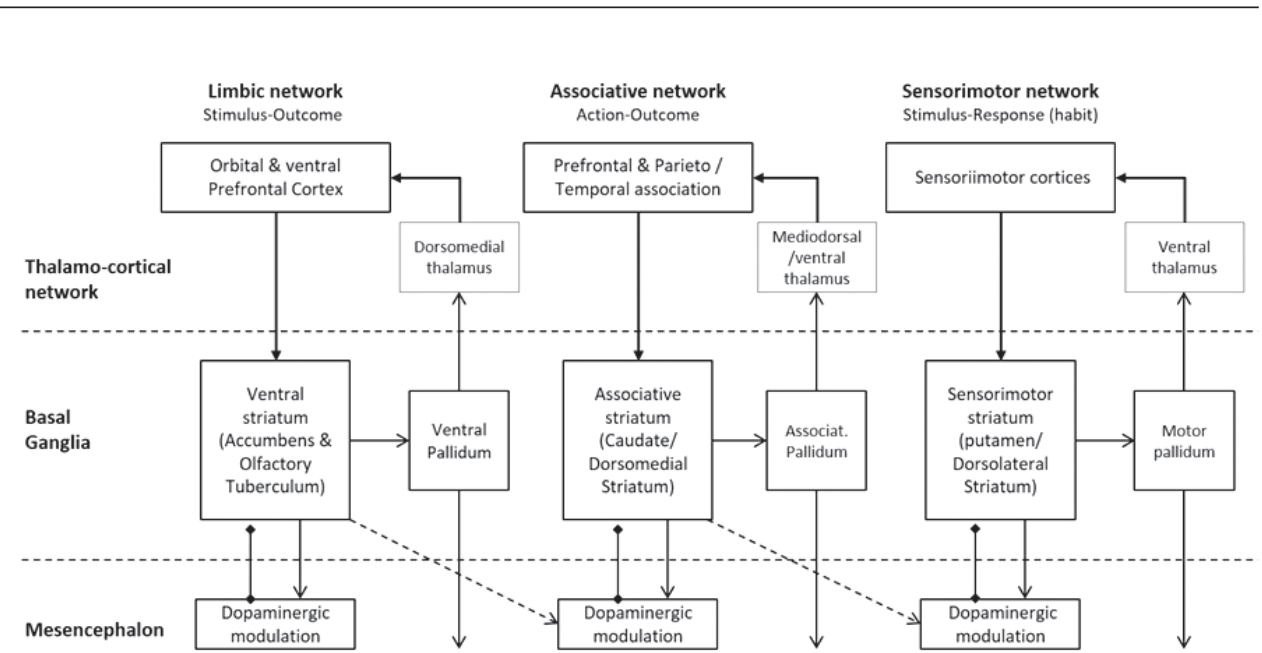

Figure 1. Unit IV. Basal ganglia systems. Three main networks: limbic, associative and sensorimotor. After Yin H.H. and Knowlton (2006)

The model of the basal ganglia system based on direct, indirect, and hyperdirect pathways (Koziol \& Budding, 2009) has been challenged in the light of new tract tracing information. Recent studies have identified a direct connection between the cortex and the external and internal segment of globus pallidus (Quartarone et al., 2020).

The limbic network is associated with situations of stimulus-outcome (S-O), as in the case of emotions or conditioned learning (the stimulus generates the outcome). Motivation plays a major role in organizing behavioral decision and actions. Although the ventral striatum is considered a motivation-action gate (Hariri, 2015), the basal ganglia integrate motivation and action across their circuits. The striosomes (one of two com- 
plementary compartments within the striatum [known as the matrix]) could contribute strongly to this merger (Courtemanche \& Cammalleri, 2019).

The associative network is associated with novelty and executive actions. Novelty implies action-outcome (A-O) contingencies (Yin H.H. \& Knowlton, 2006). Successful problem solving requires determining a synthesis of environmental information (afferent synthesis) and searching for the individual operations, which will be used to obtain the necessary results (outcome) (Koziol \& Budding, 2009).

The sensorimotor network is associated with situations of stimulus-response (S-R) and habit formation (Yin H.H. \& Knowlton, 2006). The stimulus (internal or external) triggers the appropriate response (Koziol \& Budding, 2009). A shift from the associative to the sensorimotor cortico-basal ganglia network has been observed during the process of learning (Yin H.H. \& Knowlton, 2006; Koziol \& Budding, 2009).

Basal ganglia learning: Reinforcement learning. This type of learning is based on the "evaluation of the current situation by prediction of reward" (Doya, 2000a, p. 736). It implies the "selection of appropriate action by the evaluation of candidate actions" (Doya, 2000a, p. 736). Reinforcement learning is guided by the reward signal encoded in the dopaminergic input from the substantia nigra and the ventral tegmental area (Yin H.H. \& Knowlton, 2006).

\section{Unit V: Cerebellar Systems}

Major neural structures that compose unit $\mathbf{V}$. This unit is composed of the cerebellar systems subdivided on the basis of their anatomical connectivity (see Table 5).

In recent decades, a series of studies have demonstrated and characterized the cerebellar functions beyond motor and vestibular control, including cognitive, autonomic, emotional, and social domains (Schmahmann, 2019; Schmahmann, Guell, Stoodley, \& Halko, 2019; Leggio \& Olivito, 2018). The cerebellum is of paramount importance for information computation thanks to the characteristic of its canonical circuitry, the enormous computational possibilities, and connectivity to other areas (Grimaldi \& Manto, 2012).

\section{Table 5}

Unit V (cerebellar systems): main structures. After Schmahmann et al. (2019), Schmahmann (2019)

\section{Limbic / paralimbic network (“emotional cerebellum”)}

- Limbic cerebellum (posterior vermis). Output via reticular nuclei, hypothalamus and limbic and paralimbic structures

- Cerebellar neuropsychiatric syndromes: posterior vermis lesions (interruption of cerebrocerebellar limbic loops, and related connections)

\section{Associative network ("cognitive cerebellum")}

- Cerebrocerebellum. Output via dentate nucleus to cerebral cortices

- Cognitive cerebellar syndromes: posterior lobe lesions, that affect lobules VI and VII, including Crus I, Crus, II, and lobule VIIB. (interruption of connections or impairment of cerebellar modulation of cerebral associative cortices). 


\section{Motor and vestibular network ("motor and vestibular cerebellum")}

- Spinocerebellum (paleocerebellum): (1) medial part of cerebellar hemisphere (output via interpositus nucleus [globose + emboliform nuclei]). (2) Vermis (output via fastigial nucleus). Reticular formation connections

- Cerebellar motor syndrome: lesions that affect anterior lobe and parts of lobule VI (interruption of connections with cerebral and spinal cord motor systems)

- Vestibulocerebellum (archicerebellum): flocculonodular lobe and inferior vermis. Output mainly via vestibular nuclei and extraocular muscle nuclei

- Cerebellar vestibular syndrome: lesions that affect flocculonodular lobe (interruption of connections with cerebral and brainstem vestibular and eye movement systems)

Divisions of the cerebellar systems. Cerebellar circuits are segregated into functional areas (Brodal, 1992; Grimaldi \& Manto, 2012). A classical subdivision of the cerebellum on the basis of functional differences corresponds to a subdivision on the basis of differences in the origin of the afferent fibers (Brodal, 1992).

Such division also corresponds with that based on cerebellar phylogenetic development (archicerebellum, paleocerebellum, and neocerebellun).

The archicerebellum consists of the small floculonodular lobe (the nodulus in the midline, connected laterally to the flocculus). This part of the cerebellum receives afferents primarily from the vestibular system (vestibulocerebellum). The paleocerebellun consists of the anterior and posterior parts of the vermis and adjoining parts of the intermediate zone. This part of the cerebellum receives afferents from the spinal cord (spinocerebellun). The neocerebellum consists of the lateral parts of the cerebellar hemispheres. The hemispheres receive the main input from the cerebral cortex, the cortico-ponto-cerebellar pathway (pontocerebellum). The simplified canonical cortico-cerebellar circuit is the following: cortex pons - cerebellar cortex/dentate nucleus - red nucleus - thalamus - cortex (Ito, 2006).

The three main divisions of the cerebellum act reciprocally on the parts of the CNS from which they receive their afferents: the vestibulocerebellum sends fibers mainly to the vestibular nucleus, the spinocerebellum acts on the spinal cord, and the cerebrocerebellum influences the cerebral cortex and other structures (Brodal, 1992). In summary, the cerebellar systems are involved in sensoriomotor, limbic, and associative networks (Habas, Manto, \& Cabaraux, 2019).

As previously stated, the activity of the cerebellar systems is performed in parallel with the basal ganglia (Milardi et al., 2019). Recent studies have demonstrated that the cerebellar anatomical connection pathways pass through specific subnuclei of the thalamus, the "cerebellar thalamus" (Habas et al., 2019). The central role of these connections should no longer be assimilated to a passive relay of information (Habas et al., 2019).

Studies of cases with cerebellar lesions permit the recognition of the functional topography and nature of three cerebellar syndromes: motor, vestibular, and cognitive affective (Schmahmann, 2019). Moreover, the cerebral cortical dorsal attention network 
shows strong, selective connectivity with a set of cerebellar circuits, including lobule VIIb/VIIIA (Brissendent \& Somers, 2019). These circuits exhibit functional properties characteristic of the cortical dorsal attention pathway: task-specific activation, working memory load-dependent responses, and the representation of visuospatial location. It has been suggested that parallel cortico-cerebellar pathways may play specific functional roles in a series of cognitive processes (Brissendent \& Somers, 2019).

The limbic cerebellum acts upon the reticular nuclei (effects on the arousal system), the hypothalamus via the superior cerebellar peduncle (autonomic functions), and the cingulate and other limbic structures (emotions, and emotional experience) (Turner et al., 2007; Grimaldi \& Manto, 2012). Beyond the traditional division of cerebro-cerebellar networks in sensoriomotor/cognitive modules, during emotional/social processing, the cerebellar activity shows a domain-specific mentalizing functionality that is strongly connected with the corresponding mentalizing network in the cerebrum. The phylogenetic recent lobules, such as lobules VI and VII (Crus II-II) within the posterolateral cerebellar hemisphere, have been implicated in social cognition (Leggio \& Olivito, 2018).

The universal cerebellar transform and orthometrics. Unlike the cerebral cortex, the cerebellar cortex displays histological homogeneity (a single type of canonical circuit) (Shepherd, 2004). This fact implies that it performs a constant operation, which is termed the universal cerebellar transform (UCT) (Schmahmann, 2004, 2019; Schmahmann et al., 2019). This same operation will be applied to motor, vestibular, cognitive, and limbic activities (emotional and autonomic). Following the theory of the UCT, "the cerebellum maintains behavior around a homeostatic baseline, automatically, without conscious awareness, informed by implicit learning, and performed according to context" (Schmahmann, 2019, p. 62).

In a previous paper it was proposed that the cerebellum had an orthometric physiological function (Peña-Casanova, 2018). Orthometrics (or eumetrics), as opposed to dysmetria [dyschronometria or dysrhythmia (Blumenfeld, 2010)], involves the regulation and improvement of quality, efficiency, fluidity, intensity, softness, and, finally, the adaptability of motor, cognitive, behavioral, and emotional acts. In other words, orthometria implies the adequate graduation of the quality of the strength of an impulse to match the need. The same concept of motor dysmetria (or dyschronometria) observed in cases of cerebellar lesions is applicable to cognition and emotion (Schmahmann, 2004).

Cerebellar cognitive affective syndrome is the term applied to cognitive, emotional, and behavioral symptoms that appear in patients with lesions involving the cerebellum (Schmahmann, 2004; Koziol et al., 2014). In this context, the vermal region has been referred to as the "limbic cerebellum", and focal involvement of this area has been related to disturbances in emotional responsiveness, alterations in personality, as well as psychotic and behavioral disturbances (Schmahmann, 2004, 2019; Koziol et al., 2014; Schmahmann et al., 2019). Recent studies have reportedrelationships between cerebellar development, behaviour, and complex brain disorders (Sathyanesan et al., 2019).

Cerebellar learning: supervised learning. In fact, the cerebellum is specialized in a particular kind of learning. Its function is based on "internal models of the body and the environment" (Doya, 2000a, p. 738). Cerebellar function implies the "replication 
of arbitrary input output mapping" (Doya, 2000a, p. 738) acquired in different locations of the brain. In this regard, the cerebellum has a function as a predictor or anticipator informing the cerebral cortex about the predicted outcome (Koziol \& Budding, 2009), and can be defined as a supervised learning system. The cerebellum is also related to classical conditioning (Henke, 2010).

A note on the cerebellum in Luria's work. Interestingly, an original case report from Luria's laboratory drew attention to cognitive deficits resulting from a cerebellar tumor (Kutsemilova, Luria, \& Homskaja, 1964). This case report highlighted "pseudo-frontal" symptoms and cerebellar contributions to cognition (Budisavljevic \& Rammani, 2012).

\section{Discussion}

It must be recognized that the three functional unit model of Luria (1973a) was an early contribution to neuroscience. Brain systems show an eminently vertical organization (Luria, 1973a; Koziol \& Budding, 2009) in which horizontal functional relationships also appear. This review allows us to distinguish two large integrated and interrelated functional complexes: a primordial-limbic complex and a supralimbic one.

Primordial-limbic complex. This complex consists of two large units: preferential or primordial (unit I) and limbic (unit II). In fact, Luria (1973a) was correct in integrating brainstem, hypothalamus, and limbic functions into a unique functional system. Beyond this integrated view, ontogenetic, anatomical, and functional specificities of the brainstem versus limbic systems must be recognized. Following the studies of Yakovlev (1948), unit I is related to endokinesis, while unit II is related to ereismokinesis. The hypothalamus receives and integrates external (sensory pathways) and internal stimuli (chemoreceptors, bloodstream) directly or indirectly (mainly via the limbic system). In this regard, the hypothalamus is essential for behavioral adjustments to changes in the internal or external environment (Clark et al., 2018). Thanks to these changes, the primordial survival of the individual is possible. At this point, it is important to comment on the relationships between type I and type II functional systems (Anokhin, 1935; Luria, 1973a). Type I functional systems act internally and unconsciously to maintain homeostasis thanks to endokinesis. The activation of type II functional systems involves three initial basic components: arousal, motivation, and reward (Luria, 1973a; Cabanac, 2010). Based on these components the supralimbic integrated functional complex (cortex-basal ganglia-cerebellum) will be activated. At this moment, the ascending neuromodulatory systems will mediate global signals to regulate the distributed functional mechanisms (type II) of the brain, specifically in the case of learning processes (Doya, 2002).

Supra limbic complex. This functional complex consists of the cortex (unit III) and two vertical integrated networks: basal ganglia (unit IV) and cerebellum (unit V): see Figure 2. As commented, this integrated network is topographically and functionally organized into three main systems: limbic, associative, and sensorimotor (Yin H.H. \& Knowlton, 2006), see Figure 1. 


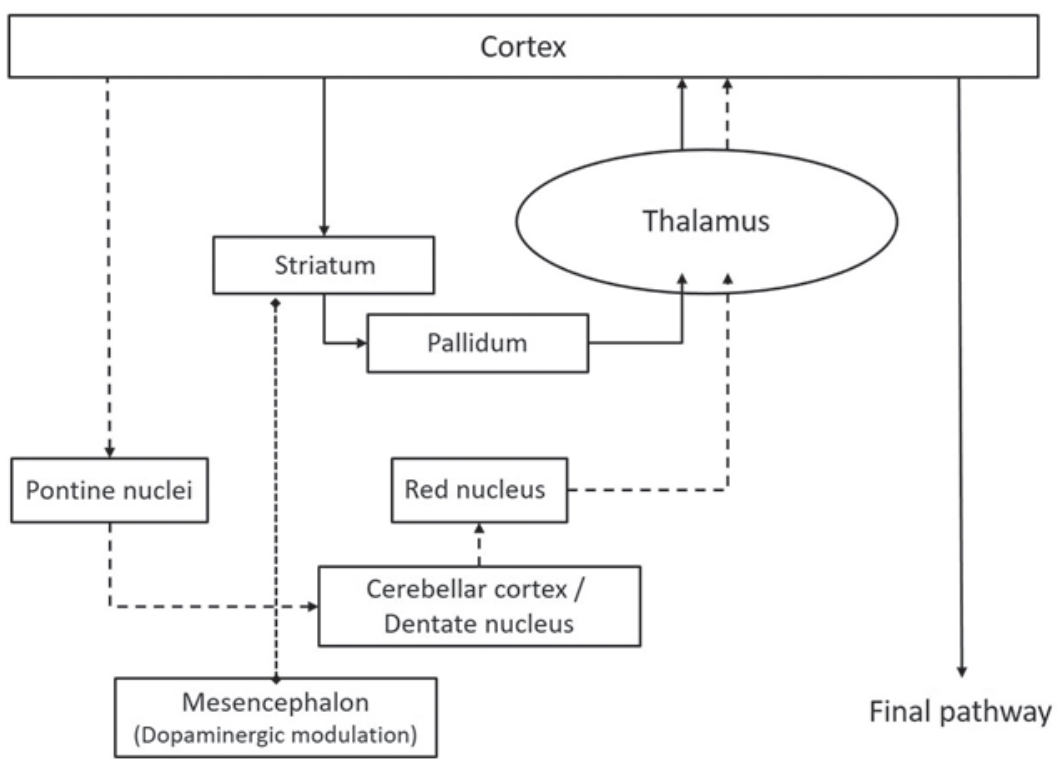

Figure 2. Simplified integrated parallel basal ganglia (unit IV) and cerebellar (unit V) circuits. Only the dorsal striatum is represented. Basal ganglia circuit: cerebral cortex, striatum, pallidum, thalamus, cerebral cortex. Mesencephalic dopaminergic pathways modulate striatal function. Cerebellar circuit: cerebral cortex, pontine nuclei, cerebellum, red nucleus, thalamus, cerebral cortex

There is a consensus regarding the existence of clear interplay among the cortex, basal ganglia, and cerebellum (Caligiore et al., 2017). Recent studies have also demonstrated that the basal ganglia and the cerebellum are interconnected at a subcortical level. The subthalamic nucleus in the BG is the source of disynaptic projections to the cerebellar cortex. Similarly, "the dentate nucleus is the source of a dense disynaptic projection to the striatum" (Bostan \& Strick, 2018, p. 338).

Local cortical processors and large-scale networks. The cerebral cortex is made up of multiple hierarchically distributed local areas [processors] (Table 3 and Figure 1) whose lesions give rise to classical cerebral focal syndromes (see the classic work of Luria, 1973a, and Mesulam's approach, 2000). Local cortical areas (with some exceptions) form parallel cortico-subcortical circuits that show an anatomical and functional continuum (see Figure 3).

In addition to local processors, the cerebral cortex displays an intense network of local, lobar, intrahemispheric, and interhemispheric horizontal connections (Catani \& Thiebaut de Schotten, 2012). It is also important to highlight here the distinction between ventral and dorsal processing pathways (Ungerleider \& Mishkin, 1982) in the visual, auditory, and somatosensory systems.

Beyond strict anatomy, seven coarse patterns of functional connectivity (networks) have been described within the human brain: visual, somatomotor, dorsal attention, 
ventral attention, limbic, frontoparietal, and default mode (Yeo et al., 2011). The neuroanatomy and connectivity of these brain networks, which include vertical connections with the basal ganglia and cerebellum, are crucial to delineate a functional brain model. The default mode network includes the medial PFC, temporoparietal junction, lateral temporal cortex, posterior cingulate cortex, and inferior frontal gyrus (Spreng \& Andrews-Hanna, 2015). This network is linked to various modes of self-generated thought, consciousness, and mental orientation in person, space, and time (Di Perri, Stender, Laureys, \& Gosseries, 2014; Peer et al., 2015).

Superlearning. As previously commented, there are several different learning mechanisms acting within the brain: unsupervised, reinforcement, and supervised (Doya, 2000b, 2002). It is also crucial to propose a model for memory systems based on processing modes rather than consciousness (Henke, 2010). It is currently recognized that "brain areas form

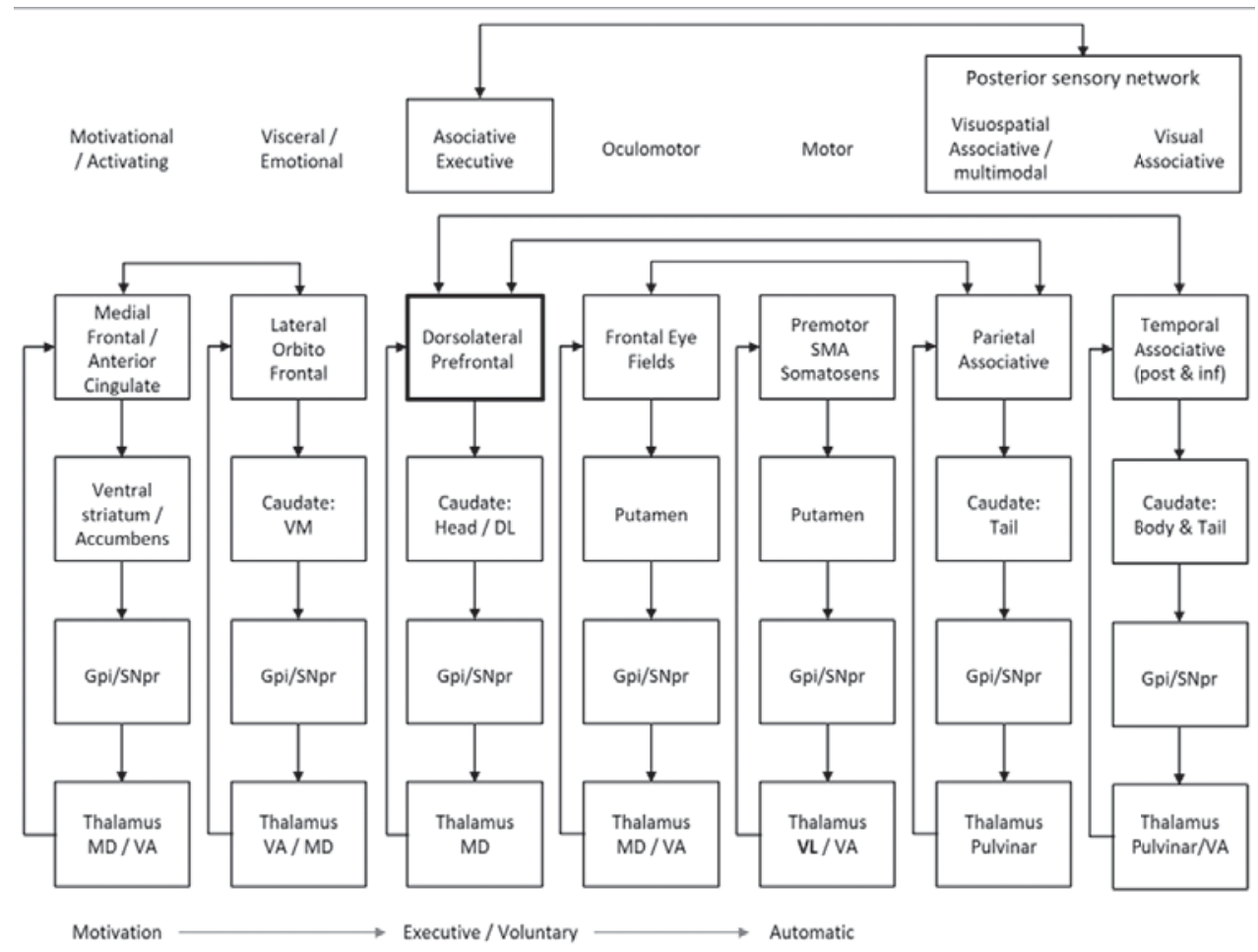

Figure 3. Representation of multiple parallel cortico-striatal-thalamic circuits (columns). Five frontal networks (left) and two posterior networks (right) are shown. The cerebral cortex is made up of local processors (rows 1 [functions], and 2 [cortical areas]). Corticocortical connections are established through association pathways (bidirectional horizontal connections). The posterior sensory processing network (parieto-temporal) connects with the dorsolateral prefrontal cortex (they constitute the executive fronto-parietal network). Bottom: topographic changes during learning (shifting from executive/voluntary networks to sensorimotor networks). After Koziol and Budding (2009), Kim and Hikosaka (2015), Seger (2006, 2008), Yin H.H. and Konwlton (2006), and Cummings and Mega (2003) 
a highly integrated system, combining different learning mechanisms into an effective super-learning process supporting the acquisition of flexible motor behavior" (Caligiore, Arbib, Miall, \& Baldassarre, 2019, p. 19). The concept of super-learning refers to the fact that different learning mechanisms act as a global synergistic functional system across the cortex, cerebellum, and basal ganglia (Caligiore et al., 2019).

In computational theories of acquisition of goal-directed behaviors, and specifically in reinforcement learning, establishing "how to set the different parameters of learning algorithms such as the speed of learning, the size of noise for exploration, and the time scale of prediction of future reward" is key (Doya, 2002, p. 495).

The parameters that globally affect the way many functional system parameters change by learning are called metaparameters or hyperparameters. Metalearning represents the "capability of dynamically adjusting its own metaparameters of learning" (Doya, 2000b, p. 495). The specific functional computational characteristics, and the reciprocal influences between the three learning processes, are influenced by the ascending neuromodulatory systems (unit I) (Doya, 2002).

Learning implies a shift (see Figure 3, bottom) from goal-directed behavior (association cortex, rostral basal ganglia) to automatic skills (sensorimotor cortex, caudal basal ganglia) (Kim \& Hikosaka, 2015). See also Seger $(2006,2008)$.

There is evidence that large scale brain connections play a key role in semantic maps and semantic cognition (Huth, de Heer, Griffiths, Theunissen, \& Gallant, 2016; Lambon-Ralph, Jefferies, Patterson, \& Rogers, 2017; Friederici, 2011; Pulvermuller, 2013).

Functional systems and neuropsychological assessment. The concept of "neuropsychological factor" (Luria, 1973a) refers (1) to the neurological impairment of a local brain area (a local processor), and (2) to the associated psychological phenomena. See Mikadze, Ardila, and Akhutina (2018) for more information. In fact, the concept of neuropsychological factor couples aspects of cognitive functioning with brain anatomy (Mikadze, 2011). Thus, qualitative symptom analysis is considered crucial in order to establish a correspondence between symptoms and lesion localization (Mikadze et al., 2018). Beyond these considerations, it is possible to integrate and combine qualitative and quantitative assessment approaches (Glozman, 1999, 2018). Advances in the knowledge of the biological foundations of complex functional systems should contribute to a refinement of neuropsychological assessment. This review highlights a new anatomical and functional approach in the syndromic analysis of brain lesions.

\section{Conclusions}

In summary, this paper attempts to describe the anatomical aspects of a functional brain model that develops Luria's ideas (Peña-Casanova, 1989). Functional units are abstractions within the global and integrated function of the brain. These abstractions are built on the basis of ontogenetic, anatomical, histological, functional, and clinical studies. As Luria (1973a) advanced, functional units show clear interaction among each other. Certain 
structures (e.g. neuromodulatory systems, hypothalamus, and paralimbic cortex) form functional links between units. It is now recognized that functional interaction is very evident in the case of the cortex, the basal ganglia, and the cerebellum. Future studies are required to develop and improve the proposed model.

\section{Limitations}

This paper has several limitations: it tries to establish components in a functional system that is global, the review has basically focused on anatomical structures. Space limitations have not allowed some details and certain issues have been left out.

\section{References}

Akhutina, T. V., \& Pylaeva, N. M. (2011). L. S. Vygotsky, A. R. Luria and developmental neuropsychology. Psychology in Russia: State of the Art, 4, 155-175. https://doi.org/10.11621 /pir.2011.0009

Amico, E., Arenas, A., \& Goñi, J. (2019). Centralized and distributed cognitive task processing in the human connectome. Network Neuroscience, 3(2), 455-474. https://doi.org/10.1162/netn_a_00072

Andersen, P., Morris, R., Amaral, D., Bliss, T., \& O'Keefe J. (Eds.) (2007). The hippocampus book. New York: Oxford University Press.

Anokhin, P. K. (1935). The problem of the center and periphery in the physiology of nervous activity. Gorki: Gosizdat.

Ardila, A. (2018). Historical development of human cognition. A cultural-historical neuropsychological perspective. Singapore: Springer.

Baker, J. T., Dillon, D. G., Patrick, L. M., Roffman, J.L., Brady, R. O., Pizzagalli, D. A., ... Holmes A. J. (2019). Functional connectomics of affective and psychotic pathology. Proceedings of the National Academy of Sciences of the United States of America, 116 (18), 9050-9059. https://doi.org/10.1073/ pnas. 1820780116

Bernard, C. (1866). Leçons sur les phénomènes de la vie communs aux animaux et aux végétaux [Lessons on the phenomena of life common to animals and plants]. Paris: Librairie philosophique J. Vrin.

Binks, D., Watson, C., \& Puelles, L. (2019). A re-evaluation of the anatomy of the claustrum in rodents and primates - Analyzing the effect of pallial expansion. Frontiers in Neuroanatomy, 13, 34. https:// doi.org/10.3389/fnana.2019.00034

Blumenfeld, H. (2010). Neuroanatomy through clinical cases ( $2^{\text {nd }}$ ed.). Sunderland, Massachusetts: Sinauer Associates.

Bostan, A. C., \& Strick, P. L. (2018). The basal ganglia and the cerebellum: Nodes in an integrated network. Nature reviews. Neuroscience, 19 (6), 338-350. https://doi.org/10.1038/s41583-018-0002-7

Brissenden, J. A., \& Somers, D. C. (2019). Cortico-cerebellar networks for visual attention and working memory. Current Opinion in Psychology, 29, 239-247. https://doi.org/10.1016/j.copsyc.2019.05.003

Brodal, P. (1992). The central nervous system. Structure and function. New York: Oxford University Press. Budisavljevic, S., \& Rammani, N. (2012). Cognitive deficits from a cerebellar tumour: A historical case report from Luria's Laboratory. Cortex, 48, 26-35. 
Cabanac, M. (2010). The dialectics of pleasures. In M.L. Kringelbach \& K. C. Berridge (Eds.), Pleasures of the brain (pp. 113-124). New York: Oxford University Press.

Caligiore, D., Arbib, M. A., Miall, R. C., \& Baldassare, G. (2019). The super-learning hypothesis: Integrating learning processes across cortex, cerebellum and basal ganglia. Neuroscience and Biobehavioral Reviews, 100, 19-34. https://doi.org/10.1016/j.neubiorev.2019.02.008

Caligiore, D., Pezzulo, G., Baldassare, G., Bostan, A. C., Strick, P. L., Doya, K., ... Herreros, I. (2017). Consensus paper: Towards a systems-level view of cerebellar function: The interplay between cerebellum, basal ganglia, and cortex. Cerebellum, 16 (1), 203-229. https://doi.org/10.1007/ s12311-016-0763-3

Cannon, W. B. (1932). The wisdom of the body. New York: W. W. Norton.

Catani, M., \& Thiebaut de Schotten, M. (2012). Atlas of human brain connections. New York: Oxford University Press.

Clark, D. L., Boutros, N. N., \& Mendez, M.F. (2018). The brain and behavior (4 ${ }^{\text {th }}$ ed.). Cambridge: Cambridge University Press.

Courtemanche, R., \& Cammalleri, A. (2019). Basal ganglia: Striosomes and the link between motivation and action. Current Biology, 29 (2), R62-R65 https://doi.org/10.1016/j.cub.2018.11.051

Cox, J., \& Witten, I. B. (2019). Striatal circuits for reward learning and decision-making. Nature Reviews. Neuroscience, 20 (8), 482-494. https://doi.org/10.1038/s41583-019-0189-2

Cummings, J.L., \& Mega, M.S. (2003). Neuropsychiatry and behavioral neuroscience. New York: Oxford University Press.

Dehghani, N., \& Wimmer, R. D. (2019). A computational perspective of the role of the thalamus in cognition. Neural Computation, 31 (7), 1380-1418. https://doi.org/10.1162/neco_a_01197

Di Perri, C., Stender, J., Laureys, S., \& Gosseries, O. (2014). Functional neuroanatomy of disorders of consciousness. Epilepsy and Behavior, 30, 28-32. https://doi.org/10.1016/j.yebeh.2013.09.014

Dolleman van der Weel, M. J, Griffin, A. L, Ito, H. T., Shapiro, M. L., Witter, M. P., Vertes, R. P., \& Allen, T.A. (2019). The nucleus reuniens of the thalamus sits at the nexus of a hippocampus and medial prefrontal cortex circuit enabling memory and behavior. Learning \& Memory, 26 (7), 191-205. https://doi.org/10.1101/lm.048389.118

Doya, K. (2000a). Complementary roles of basal ganglia and cerebellum in learning and motor control. Current Opinion Neurobiology, 10 (6), 732-739. https://doi.org/10.1016/s0959-4388(00)00153-7

Doya, K. (2000b). Metalearning, neuromodulation, and emotion. In G. Hatano, N. Okada, \& H. Tanabe (Eds.), Affective Minds. Amsterdam: Elsevier.

Doya, K. (2002). Metalearning and neuromodulation. Neural Networks, 15 (4-6), 495-506. https://doi. org/10.1016/s0893-6080(02)00044-8

Druga, R. (2014). The structure and connections of the claustrum. In J. R. Smithies, R. L. Edelstein, \& V.S. Ramachandran (Eds.), The claustrum, structural, functional and clinical neuroscience (pp. 28-84). New York: Academic Press.

Friederici, A. D. (2011). The brain basis of language processing: from structure to function. Physiological Reviews, 91 (4), 1357-1392. https://doi.org/10.1152/physrev.00006.2011

Glozman, J. M. (1999). Quantitative and qualitative integration of Lurian procedures. Neuropsychology Review, 9 (1), 23-32. https://doi.org/10.1023/a:1025638903874 
Glozman, J. M. (2018). Forty years without Luria with Luria. In J. M. Glozman, O. S. Vindeker, I. A. Ershova, \& M.E. Permiakova (Eds.), The Fifth International Luria Memorial Congress "Lurian approach in international psychological science”, KnE Life Sciences, 1-11. https://doi.org/10.18502/ kls.v4i8.3257

Gould, S., \& Vrba, E. S. (1982). Exaptation - A missing term in the science of form. Paleobiology, 8, 4-15. Grillner, S., \& Robertson, B. (2016). The basal ganglia over 500 million years. Current Biology, 26 (20), R1088-R1100. https://doi.org/10.1016/j.cub.2016.06.041

Grimaldi, G., \& Manto, M. (2012). Topography of cerebellar deficits in humans. The Cerebellum, 11 (2), 336-351. https://doi.org/10.1007/s12311-011-0247-4

Habas, C., Manto, M., \& Cabaraux, P. (2019). The cerebellar thalamus. Cerebellum, 18 (3), 635-648. https://doi.org/10.1007/s12311-019-01019-3

Hannula, D. E., \& Duff, M. C. (2017). The hippocampus from cells to systems. Cham: Spinger.

Hariri, A. R., (2015). Looking inside the disordered brain. Sunderland, Massachusetts: Sinauer Associates.

Henke, K. (2010). A model for memory systems based on processing modes than consciousness. Nature Reviews. Neuroscience, 11 (7), 523-532. https://doi.org/10.1038/nrn2850

Huth, A. G., de Heer, W.A., Griffiths, T.L., Theunissen, F.E., \& Gallant, J. L. (2016). Natural speech reveals the semantic maps that tile human cerebral cortex. Nature, 532 (7600), 453-458. https:// doi.org/10.1038/nature17637

Hwang, K., Bertolero, M. A., Liu, W. B., \& D’Esposito, M. (2017). The human thalamus is an integrative hub for functional brain networks. The Journal of Neuroscience, 37 (23), 5594-5607. https://doi. org/10.1523/JNEUROSCI.0067-17.2017

Ito, M. (2006). Cerebellar circuitry as a neuronal machine. Progress in Neurobiology, 78 (3-5), 272-303. https://doi.org/10.1016/j.pneurobio.2006.02.006

Jaramillo, J., Mejias, J.F., \& Wang, X. J. (2019). Engagement of pulvino-cortical feedforward and feedback pathways in cognitive computations. Neuron, 101 (2), 321-336.e9. https://doi.org/10.1016/j. neuron.2018.11.023

Jubert, J., (1983). Filogènesi del sistema nerviós. La imatge o idea de l'home construïda per les neurociències [Phylogenesis of the nervous system. The image or idea of the man constructed by the neurosciences]. Estudi general, 3, 63-61.

Kennedy, H., Van Essen, D. C., \& Christen, Y. (Eds.). (2016). Micro-, meso- and macro- connectomics of the brain. Cham: Springer.

Kim, H. F., \& Hikosaka, O. (2015). Parallel basal ganglia circuits for voluntary and automatic behavior to reach rewards. Brain: Journal of Neurology, 138 (Pt. 7), 1776-1800. https://doi.org/10.1093/ brain/awv134

Koziol, L. F., \& Budding, D. E. (2009). Subcortical structures and cognition. New York: Springer.

Koziol, L. F., Budding, D., Andreasen, N., D’Arrigo, S., Bulgheroni, S., Imamizu, H., ... Yamazaki, T. (2014). Consensus paper: The cerebellum's role in movement and cognition. Cerebellum, 13 (1), 151-177. https://doi.org/10.1007/s12311-013-0511-x

Kutsemilova, A. P., Luria, A. R., \& Homskaja, E. D. (1964). Analisi neuropsicologica di una syndrome pseudo-frontale da tumore cerebellare [Neuropsychological analysis of a pseudo-frontal syndrome from a cerebellar tumor]. Cortex, 1 (3), 291-301. https://doi.org/10.1016/S0010-9452(64)80004-6 
Lambon-Ralph, M.A., Jefferies, E., Patterson, K., \& Rogers, T. T. (2017). The neural and computational bases of semantic cognition. Nature Reviews. Neuroscience, 18(1), 42-55. https://doi.org/10.1038/ nrn.2016.150

Lange, S. C., Scholtens, L.H., van den Berg, L.H., Boks, M. P, Bozzali, M., Cahn, W., ... Heuvel, M.P. (2019). Shared vulnerability for connectome alterations across psychiatric and neurological brain disorders. Nature Human Behavior, 3, 988-998. https://doi.org/10.1038/s41562-019-0659-6

Lautin, A. (2002). The limbic brain. New York: Kluwer Academic Publishers.

Lecours, A.R., \& Simard, M. (1998). Cerebral substrate of language. Ontogenesis, senescence, aphasia and recoveries. In B. Stemmer \& H. A. Whitaker (Eds.), Handbook of neurolinguistics (pp. 17-24). San Diego: Academic Press.

Leggio, M., \& Olivito, G. (2018). Topography of the cerebellum in relation to social brain regions and emotions. In M. Monto \& T. A. G. M. Huisman (Eds.), Handbook of Clinical Neurology. The cerebellum: From embryology to diagnostic investigations ( $3^{\text {rd }}$ ser. Vol. 154, pp. 71-84). Amsterdam: Elsevier. https://doi.org/10.1016/B978-0-444-63956-1.00005-9

Leontiev, A. N. (1959). Problems on mental development. Moscow: Editions of the Academy of Pedagogical Sciences of the RSFSR. [In Russian]

Luria, A. R. (1973a). Fundamentals of neuropsychology. Moscow: Moscow University Press. [In Russian]

Luria, A. R. (1973b). The working brain. An introduction to neuropsychology. London: Penguin press. Penguin Books.

Luria, A. R. (1974). On the historical development de cognitive processes. Moscow: Nauka. [In Russian]

Macpherson, T., \& Hikida, T. (2019). Role of basal ganglia neurocircuitry in the pathology of psychiatric disorders. Psychiatry and Clinical Neurosciences, 73 (6), 289-301. https://doi.org/10.1111/pcn.12830

Maren, S., Phan, K. L., \& Liberzon, I. (2013). The contextual brain: implications for fear conditioning, extinction and psychopathology. Nature Reviews Neuroscience, 14, 417-428. https://doi. org/10.1038/nrn3492

Mathur, B. N. (2014). The claustrum in review. Frontiers in systems in neuroscience, 8, 48. https://doi. org/10.3389/fnsys.2014.00048

McFarland, D. J., \& Sibly, R. M. (1975). The behavioural final common path. Philosophical Transactions Royal Society London. Ser. B, Biological sciences, 270 (907), 265-293. https://doi.org/10.1098/ rstb.1975.0009

Mesulam, M. M. (2000). Principles of behavioral and cognitive neurology. New York: Oxford.

Mikadze, Y.V. (2011). Methodology of neuropsychological assessment: qualitative (metasyndromal analysis of cognitive deficit structure) and quantitative (psychometric estimate). Psychology in Russia: State of the Art, 5, 261-267. https://doi.org/10.11621/pir.2011.0015

Mikadze, Y. V, Ardila, A., \& Akhutina, T. (2018). A. R. Luria’s approach to neuropsychological assessment and rehabilitation. Archives of Clinical Neuropsychology, 34 (6), 795-802. https://doi.org/10.1093/ arclin/acy095

Milardi, D., Quartarone, A., Bramanti, A., Anastasi, G., Bertino, S., Basile, G. A., .. Cacciola, A. (2019). The cortico-basal ganglia-cerebellar network: past, present and future perspectives. Frontiers in systems neuroscience, 13, 61. https://doi.org/10.3389/fnsys.2019.00061

Pandya, D. N., Seltzer, B., Petrides, M., \& Cipolloni, P. B. (2015). Cerebral cortex: architecture, connections, and the dual origin concept. New York: Oxford University Press. 
Parvizi, J. (2009). Corticocentric myopia: old bias in new cognitive sciences. Trends in Cognitive Sciences, 13 (8), 354-359. https://doi.org/10.1016/j.tics.2009.04.008

Peer, M., Salomon, R., Goldberg, I., Blanke, O., \& Arzy, S. (2015). Brain systems for mental orientation in space, time, and person. Proceedings of the National Academy of Sciences of the United States of America, 112 (35), 11072-11077. https://doi.org/10.1073/pnas.1504242112

Peña-Casanova, J. (1989). A. R. Luria today: Some notes on "Lurianism" and the fundamental bibliography of A. R. Luria. Journal of Neurolinguistics, 4, 161-178. https://doi.org/10.1016/09116044(89)90012-2

Peña-Casanova, J. (2018). Functional organization of the brain and psychic activity: a view beyond Luria (with Luria). In J. M. Glozman, O. S. Vindeker, I. A. Ershova, \& M. E. Permiakova (Eds.), The Fifth International Luria Memorial Congress "Lurian approach in international psychological science", KnE Life Sciences, 711-725. https://doi.org/10.18502/kls.v418-3329.

Pulvermuller, F. (2013). How neurons make meaning: brain mechanisms for embodied and abstract-symbolic semantics. Trends in Cognitive Sciences, 17 (9), 458-470. https://doi.org/10.1016/j. tics.2013.06.004

Quartarone, A., Cacciola, A., Milardi, D., Ghilardi, M. F, Calamuneri, A., Chillemi, G., ... Rothwell, J. (2020). New insights into cortico-basal-cerebellar connectome: clinical and physiological considerations. Brain, 143 (2), 396-406. https://doi.org/10.1093/brain/awz310

Sander, D., Grafman, J., \& Zalla, T. (2003) The human amygdala: an evolved system for relevance detection. Reviews in the Neurosciences, 14 (4), 303-316. https://doi.org/10.1515/revneuro.2003.14.4.303

Sanides, F. (1969). Comparative architectonics of neocortex of mammals and their evolutionary interpretation. Annals of New York Academy of Sciences, 167, 404-423. https://doi.org/10.1111/j.1749-6632.1969. tb20459

Sathyanesan, A., Zhou, J., Scafidi, J., Heck, D. H., Sillitoe, R. V., \& Gallo, V. (2019). Emerging connections between cerebellar development, behaviour and complex brain disorders. Nature Reviews. Neuroscience, 20 (5), 298-313. https://doi.org/10.1038/s41583-019-0152-2

Schmahmann, J.D. (2004). Disorders of the cerebellum: ataxia, dysmetria of thought, and cerebellar cognitive affective syndrome. The Journal of Neuropsychiatry and Clinical Neuroscience, 16 (3), 367-378. https://doi.org/10.1176/jnp.16.3.367

Schmahmann, J.D. (2019). The cerebellum and cognition. Neuroscience Letters, 688, 62-75. https://doi. org/10.1016/j.neulet.2018.07.005

Schmahmann, J.D., Guell, X., Stoodley, C. J., \& Halko, M. A. (2019). The theory and neuroscience of cerebellar cognition. Annual Review of Neuroscience, 42, 337-364. https://doi.org/10.1146/ annurev-neuro-070918-050258

Seeley, W. W., \& Sturm, V.E. (2007). Self-representation and the frontal lobes. In B. L. Miller \& J. L. Cummings (Eds.), The human frontal lobes. New York: The Guilford Press.

Seger, C. A. (2006). The basal ganglia in human learning. Neuroscientist, 12 (4), 285-290. https://doi. org/10.1177/1073858405285632

Seger, C. A. (2008). How do the basal ganglia contribute to categorization? Their roles in generalization, response selection, and learning via feedback. Neuroscience and Biobehavioral Reviews, 32 (2), 265-278. https://doi.org/10.1016/j.neubiorev.2007.07.010

Shepherd, G. M. (2004). The synaptic organization of the brain. New York: Oxford. 
Simonyan, K. (2019). Recent advances in understanding the role of the basal ganglia. F1000Research, 8, 122. https://doi.org/10.12688/f1000research.16524.1

Smith, K., Bastin, M.E., Cox, S. R., Valdés Hernández, M.C., Wiseman, S., Escudero, J., \& Sudlow, C. (2019). Hierarchical complexity of the adult human structural connectome. NeuroImage, 191, 205-215. https://doi.org/10.1016/j.neuroimage.2019.02.028

Sporns, O. (2016). Connectome networks: from cells to systems. In H. Kennedy, D. C. Van Essen, \& Y. Christen (Eds.), Micro-, meso- and macro- connectomics of the brain (pp. 107-127). Cham: Springer.

Spreng, R. N., \& Andrews-Hanna, J. R. (2015). The default network and social cognition. In A. W. Toga (Ed.), Brain mapping: an encyclopedic reference (pp. 165-169). New York: Academic Press.

Stephenson-Jones, M., Samuelsson, E., Ericsson, J., Robertson, B., \& Grillner, S. (2011). Evolutionary conservation of the basal ganglia as a common vertebrate mechanism for action selection. Current Biology, 21 (13), 1081-1091. https://doi.org/10.1016/j.cub.2011.05.001

Téllez, A., \& Sánchez, T. (2016). Luria's model of the functional units of the brain and the neuropsychology of dreaming. Psychology in Russia: State of the Art, 9(4), 80-93. https://doi.org/10.11621/ pir.2016.0407

Torgerson, C., \& Van Horn, J. D. (2014). A case study in connectomics: the history, mapping, and connectivity of the claustrum. Frontiers in Neuroinformatics, 8, 83. https://doi.org/10.3389/ fninf.2014.00083

Turner, B. M., Paradiso, S., Marvel, C. L., Pierson, R., Boles Ponto, L. L., Hichwa, R. D., \& Robinson, R. G. (2007). The cerebellum and emotional experience. Neuropsychologia, 45, 1331-1341. https://doi. org/10.1016/j.neuropsychologia.2006.09.023

Ungerleider, L. G., \& Mishkin, M. (1982). Two cortical visual systems. Analysis of visual behavior. Cambridge: MIT Press.

Van den Heuvel, M. P., \& Sporns, O. (2019). A cross-disorder connectome landscape of brain dysconnectivity. Nature reviews. Neuroscience, 20 (7), 435-446. https://doi.org/10.1038/s41583-019-0177-6

Vygotsky, L.S. (1960). Development of the higher mental functions. Moscow: Editions of the Academy of Pedagogical Sciences of the RSFSR. [In Russian]

Vygotsky, L. S. (1965). Psychology and localization of function. Neuropsychologia, 3, 381-386. https:// doi.org/10.1016/0028-3932(65)90011-4

Vogt, B. A. (Ed.). (2009). Cingulate neurobiology and disease. New York: Oxford University Press.

Whalen, P. J., \& Phelps, E. A. (Eds.). (2009). The human amygdala. New York: Guilford Press.

Wolff, M., \& Vann, S. D. (2019). The cognitive thalamus as a gateway to mental representations. The Journal of Neuroscience, 39 (1), 3-14. https://doi.org/10.1523/JNEUROSCI.0479-18.2018

Yakovlev, P. I. (1948). Motility, behavior, and the brain. The Journal of Nervous and Mental Diseases, 107 (4), 313-335. https://doi.org/10.1097/00005053-194810740-00001

Yeo, B. T., Krienen, F. M., Sepulcre, J., Sabuncu, M. R., Lashkari, D., Hollinshead, M., ... Buckner, R. L. (2011). The organization of the human cerebral cortex estimated by intrinsic functional connectivity. Journal of Neurophysiology, 106 (3), 1125-1165. https://doi.org/10.1152/jn.00338.2011

Yin, B., Terhune, D. B., Symthies, J., \& Meck, W.H. (2016). Claustrum, consciousness, and time perception. Current Opinion in Behavioral Sciences, 8, 258-267. https://doi.org/10.1016/j.cobeha.2016.02.032 
Yin, H.H., \& Knowlton, B. J. (2006). The role of the basal ganglia in habit formation. Nature Reviews. Neuroscience, 7 (6), 464-476. https://doi.org/10.1038/nrn1919

Original manuscript received February 4, 2020

Revised manuscript accepted March 18, 2020

To cite this article: Peña-Casanova, J., \& Sigg-Alonso, J. (2020). Functional Systems and Brain Functional Units Beyond Luria, With Luria: Anatomical Aspects. Lurian Journal, 1 (1), 48-76. DOI:10.15826/Lurian.2020.1.1.6 